\title{
S5ynthesis
}

International Scientific Conference of IT and Business-Related Research

\section{MOGUĆNOSTI INVESTIRANJA MONETARNOG ZLATA SA ASPEKTA CENTRALNE BANKE}

\author{
MONETARY GOLD INVESTMENT \\ OPPORTUNITIES FOR CENTRAL BANKS \\ Tijana Šoja ${ }^{1}$, Zumreta Galijašević ${ }^{2}$, Alen Selimović ${ }^{3}$ \\ ${ }^{1}$ Centralna banka Bosne i Hercegovine, Sarajevo, BIH \\ ${ }^{2}$ Univerzitet „Vitez“ Vitez, BIH \\ ${ }^{3}$ Hypo Alpe-Adria-Bank, dd Mostar, Mostar, BIH
}

\begin{abstract}
Apstrakt:
Poznato je da se centralne banke ubrajaju u najveće vlasnike zlata, odnosno zlatnih rezervi. Tokom perioda krize, koja je još uvijek aktuelna, centralne banke zemalja širom sveta su povećavale zlatne rezerve. S obzirom da se devizne rezerve zlata uglavnom drže u formi fizičkog zlata, postavlja se pitanje njihovog efikasnijeg korišćenja, odnosno efikasnijeg investiranja. Autori ovom prilikom ukazuju na mogućnosti koje stoje pred centralnim bankama u domenu efikasnijeg upravljanja portfoliom monetarnog zlata. Rezultati istraživanja pokazuju da je tokom kriznog perioda došlo do naglog pada kamatnih stopa na "zlatne" depozite i svopove na zlato, ali su ove stope i dalje nešto veće u odnosu na klasične kamatne stope na depozite ili prinose hartija od vrijednosti.
\end{abstract}

\section{Ključne reči:}

investiranje, "zlatni" depoziti, svopovi na zlato.

\section{UVOD}

Monetarno zlato je kroz istoriju bilo posebno važna aktiva centralnih banaka. Jačanje i razvoj krize značajno su uzdrmali tržište zlata te je u situacijama pojačane krize i likvidnosti na tržištu došlo do ogromnog rasta tražnje za zlatom, te je vrijednost ove aktive tokom 2010. godine dostigla rekordno visoke nivoe. Kako je dolazilo do povećanja vrijednosti zlata, tako su druge opcije investiranja u zlato, zlatni depoziti i svop stope na zlato, postajale manje atraktivne. Ovom prilikom će se prikazati mogućnosti investiranja monetarnog zlata u formi „zlatnih“ svopova i „zlatnih“ depozita koji su primjenljivi za investiranje monetarnog zlata koji se nalazi u portfolijima centranih banaka, te njihovo poređenje sa kamatnim stopa na tržištu. Za osnovu poređenja analizirane su kamatne stope na hartije od vrijednosti Njemačke.

\section{TRENDOVI INVESTIRANJA MONETARNOG ZLATA}

Krajem 2014. godine tržište zlata je imalo snažnu podršku sa aspekta tražnje za ovom aktivom. Tačnije, tokom IV kvartala tražnja za zlatom je povećana za $6 \%$ u odnosu na kvartal ranije. Ipak, ukupna godišnja tražnja za zlatom je smanjena za 4\%. Nakon značajnih kupovina zlata od strane centralnih banaka tokom poslednjih godina, postavilo se pitanje da li će se isti trend nastaviti i tokom 2014. godine. Prema podacima

\section{Abstract:}

It is well-known that the central banks are among major holders of gold, i.e., gold reserves. During the crisis, the central banks worldwide have increased their gold reserves. Given that foreign exchange reserves of gold are mostly held as physical gold, the question arises concerning their more efficient use, i.e., efficient investments. The authors shall hereby indicate the opportunities available to central banks in the domain of more efficient monetary gold portfolio management. Research results indicate a sudden and sharp decrease of interest rates paid for gold deposits and gold swaps during the crisis, which are still slightly greater than the classic interest rates for deposits or income securities.

\section{Key words:}

investments, gold deposits, gold swaps.

koje je objavio World Gold Council, tokom 2014. godine centralne banke su bile neto kupci zlata te je tokom 2014. godine od strane centralnih banaka kupljeno 477 t zlata, što je za $17 \%$ više u odnosu na 2013. godinu, kada su centralne banku kupile 409t zlata. Ovi podaci potvrđuju da su centralne banke, drugu godinu zaredom, bile neto kupci zlata u poslednjih 50 godina. Najveći kupac zlata, tokom 2014. godine, bila je Rusija koja je u ovom periodu kupila 173 t zlata (36\% ukupne tražnje za zlatom tokom 2014. godine). Značajni kupci zlata bili su i Kazahstan, koji je kupio 48 t zlata, Irak koji je kupio 48t zlata i Azerbejdžan koji je kupio 10t zlata. Što se tiče prodaja zlata, Ukrajina je bila jedina zemlja koja je značajno smanjila zlatne rezerve tokom 2014. godine. Ovaj zemlja je u 2014. godini smanjila rezerve zlata za $44 \%$, te njene rezerve sada iznose 24 t. S obzirom da centralne banka posjeduju značajne zalihe zlata, postavlja se pitanje efikasnijeg upravljanja ovom imovinom.

Centralne banke, pored stalne kupovine i prodaje monetarnog zlata, odnosno aktivnih trgovina ovom imovinom, imaju mogućnost da efikasnije upravljaju zlatom investirajući ga u „zlatne“ depozite ili svopove na zlato.

\subsection{INVESTICIJE U MONETARNO ZLATO}

Monetarno zlato sigurno je jedna od najvažnijih aktiva u koje se investira na globalnim finansijskim tržištima. U ovaj tip aktive investiranju brojni investitori a među njima, sigurno, prednjače centralne banke koje monetarno zlato drže zbog različitih potreba. Što se tiče mogućnosti investiranja u monetarno 
zlato, moguće su sledeće opcije (Michaud et al., 2006):

- Investicije u fizičko zlato - kupovina zlatnih poluga, nakita ili zlatnih kovanica,

- Investicije u „elektronsko“ zlato,

- Investiranje u fučerse na zlato i druge izvedene hartije od vrijednosti koje kao osnovu imaju zlato,

- Investiranje u kompanije koje se bave iskopom i proizvodnjom zlata.

Centralne banke prilikom investiranja u zlato, uglavnom se odlučuju za opciju fizičkog zlata koje se najčešće skladišti i čuva $\mathrm{u}$ velikim centralnim banakama koje imaju za to prilagođene uslove. Na primjer, u Evropi Centralna banka Engleske je jedna od najaktivnih banaka u području čuvanja zlata. Isto tako, postoji mogućnost da centralne banke investiraju u elektronski oblik zlata, pri čemu dobijaju elektronske zapise o vlasništvu nad određenom količnom zlata (Harmston, 1998). Važno je naglasiti da se zlato izražava u uncama te da je standard prilikom trgovanja 32.000 unci. Tačnije, kada se donese odluka o kupovini ili prodaji zlata tada je minimalni iznos 32.000 unci. Naravno, postoji mogućnost da se kupe i „krnji“ iznosi, npr. 40.000 unci, ali se tada dobijaju nešto nepovoljnije cijene i na tržištu često nije moguće pronaći nestanadrizovane veličine. U ovom kontekstu važno je dodati da centralne banke kupuju visokokvalitetno zlato koje mora da zadovolji sve standarde ${ }^{1}$. Prilikom donošenja odluke o kupovini zlata, centralna banka je dužna, da, u prvom redu, donese odluku o lokaciji zlata, odnosno lokaciji na kojoj će se zlato skladištiti. Lokacija zlata označava mjesto gdje se zlato fizički nalazi. Na primjer, ukoliko je zlato locirano u Londonu, tada važi sljedeće (Takeda, 2006):

- zlato se drži u Londonu,

- cijena zlata se kotira uz uslov da se zlato dostavlja tamo, odnosno u London,

- mnoge banke i milioni drugih trgovaca kotiraju cijenu na ovoj lokaciji automatski, dok mnogi investitori teže da budu dio ove transakcije odnosno ne žele zlato koje je locirano u Londonu.

Ovaj opis se ne vezuje isključivo za London. Zlato može biti locirano u Cirihu, Njujorku, Tokiju ili bilo kojem drugom finansijskom centru koji nudi ove usluge.

\subsection{RAČUNI DRŽANJA MONETARNOG ZLATA}

Prilikom držanja fizičkog zlata centralnim bankama se daje nekoliko mogućnosti koje mogu koristiti. Centralna banka može da otvori i da koristi račun alociranog zlata. U tom slučaju, centralna banka posjeduje fizičko zlato, za što važi sljedeće (Wright \& Brown, 2006):

- Kovanice zlata, zlatne poluge su brojčano označene i identifikovane određenim žigom kojim se potvrđuje težina i čistoća zlata koja je alocirana od strane njenog vlasnika koji plaća depozitaru za čuvanje i osiguranje određene količine zlata;

- Vlasnik alociranog zlata ima puno pravo na vlasništvo fizičkog zlata koje je alocirano prema određenom računu;

- Institucija kod koje se drži zlato nema pravo da prodaje, pozajmljuje ili čini bilo kakve aktivnosti sa zlatom koje čuva odnosno koje skladišti. Bilo kakve radnje moraju biti određene od strane vlasnika putem specifične instrukcije;

- Troškovi su veoma važni i podrazumjevaju naknadu držanja zlata i rukovanja zlatom kao i troškove fizičkog transfera zlata, vaganja, premještanja...

1 Misli se na standarizovane valičine unce i čistoću zlata kojim se trguje.
Centralna banka može koristiti segregirane i nesegregirane račune (odvojeni i zbirni račun). Segregirani račun podrazumjeva da se zlato fizički drži odvojeno od zlata ostalih klijenata te niko ne može imati pristup ovim zlatnim rezervama. Nesegregirani račun znači da je zlato uskladišteno zajedno sa ostalim zlatnim rezervama, sa zlatnim rezervama drugih klijenata gdje nije posebno određeno ko je vlasnik koje zlatne rezerve, odnosno ko je specifični vlasnik tačno određene unce, unce zlata određenog serijskog broja (Robert et al., 2007). Zapravo, postoji dokaz o vlasništvu nad tačno određenom količinom zlata ali nije specifikovano koje zlatne poluge pripadaju isključivo određenom vlasniku. Ovakav tip računa jedino je primljenljiv ukoliko se radi o standardizovanom zlatu, odnosno standardnim uncama zlata koje imaju jednaku čistoću, težinu i ostale karakteristike. Postoji mogućnost da centralne banke posjeduju račun nealociranog zlata. Nealocirano zlato je zapravo depozit koji postaje aktiva banke, njena imovina. Vlasnik nealociranog zlata zapravo ne posjeduje zlato u fizičkom smislu te je on jednostavno povjerilac koji posjeduje zlato ili bi barem trebalo da posjeduje zlato. Ovakve rezerve zlata se mogu prodati i time pokriti određeni rashodi ili jednostavno, ova sredstva preusmjeriti u druge investicije, ali ovakav način držanja zlata ne može biti zaštita od bankrotstva. U ovom smislu postoje dvije podkategorije - one koje su podržane fizičkim zlatom ili one koje nisu. Nealocirano zlato podržano fizičkim zlatom - u ovom slučaju vlasnici zlata kao elektronskog zapisa imaju posebnu kaluzulu koja vlasnika klasifikuje kao povjerioca u slučaju bankrotstva (Doran, 1998).

Ovim se njemu daje prioritet u odnosu na druge povjerioce. Zlato koje nije podržano fizičkim zlatom zapravo je najrizičniji vid investiranja. Ne postoji direktna potvrda da je elektronsko zlato pokriveno fizičkim zalihama zlata. Prilikom određivanja načina investiranja u zlato veoma je važno načiniti kvalitetan izbor, u zavisnosti od onoga što se investicijom želi postići. Stoga ove mogućnosti možemo predstaviti na sljedeći način:

\begin{tabular}{|c|c|c|}
\hline & Prednosti & Nedostaci \\
\hline $\begin{array}{c}\text { Alocirano } \\
\text { zlato }\end{array}$ & Sigurnost & $\begin{array}{c}\text { Troškovi, složen } \\
\text { sistem }\end{array}$ \\
\hline $\begin{array}{c}\text { Nealocira- } \\
\text { no zlato }\end{array}$ & $\begin{array}{c}\text { Fleksibilnost, niži } \\
\text { troškovi }\end{array}$ & $\begin{array}{c}\text { Rizik institucije koja } \\
\text { drži zlato }\end{array}$ \\
\hline
\end{tabular}

Tabela 1. Mogućnosti „zlatnih“ računa

Najčešći oblici korištenja računa, odnosno načina držanja zlata, jesu sljedeće kombinacije:

- alocirano segregirano (npr. drži se kod Centralne banke Engleske),

- nealocirano podržano fizičkim zlatom.

\section{MOGUĆNOSTI INVESTIRANJA MONETARNOG ZLATA CENTRALNIH BANAKA}

Mnoge centralne banke u svijetu posjeduju monetarno zlato, fizičko zlato u u alociranoj ili nealociranoj formi, koje u značajnoj mjeri investiraju. Postoje dvije mogućnosti pod kojima se zlato, ukoliko se čuva u formi fizičkog alociranog računa, može investirati:

- Zlatni svop (Gold swaps),

- Zlatni depozit.

U nastavku će se analizirati suština ovih poslova, način provođenja ovih investicija kao i generisanje prihoda po obje investicijske mogućnosti. 


\subsection{ZLATNI SVOP (GOLD SWAPS)}

„Zlatni“ svop nije ništa drugo do klasičan repo ${ }^{2}$ posao u kojem se, umjesto hartije od vrijednosti pozajmljuje zlato. Monetarne vlasti posuđuju zlato drugoj strani (drugoj banci koja je specijalizovana za obavljanje ovih poslova) u zamjenu za gotovinu, uz obavezu da zlato otkupe (monetarna vlast) na određeni dan u budućnosti po unaprijed dogovorenoj cijeni. Monetarne vlasti ove investicije najčešće poduzimaju kada žele da ostvare dodatne prihode ili da osiguraju novčana sredstva bez da u potpunosti prodaju zlato koje posjeduju. S obzirom da se ovaj posao svodi na repo poslove, tako je i u ovom slučaju neophodno poduzeti sve druge aktivnosti koje se tiču novčanih tokova, dogovora oko buduće cijene zlata (forvard cijene) i računovostvenog tretmana, koji su neophodni i u repo poslovima. Ukoliko centralna banka posjeduje zlato i ukoliko ga želi efikasnije koristiti, u ovoj transakciji vrši prodaju zlata uz obavezu njegovog otkupa $\mathrm{u}$ određenom periodu u budućnosti po unaprijed dogovorenoj cijeni.

Investiranje monetarnog zlata na osnovu zlatnih svopova je značajno smanjeno tokom razvoja finansijske krize, dok je tokom 2014. godine došlo do daljeg pada ove stope, te su stope na jedan mjesec zabilježile negativne nivoe. Investiranje na ovim osnovama podrazumijeva uključivanje svop/forvard stope, fiksinga zlata sa $\mathrm{LMBA}^{3}$ kao i perioda na koji se zlato investira. U ovim aktivnostima nema nikakvih inicijalnih margina niti „haircut-a“, nije potrebno vršiti nikakva usklađivanja po osnovu promjene cijene zlata, jer je cijena po kojoj se vrše transakcije zlatom ista kao i cijena po kojoj se zlato prodaje na dospijeću ugovora. Mogućnosti koje centralna banka u ovom slučaju ima jesu te da dobija novčana sredstva koja može koristiti u periodu od mjesec dana (ili neki drugi period na koji se želi investirati) te može sredstva investirati u formi depozita ili trezorskog zapisa i na tom osnovu realizovati određene prihode. Da bi se obavljali poslovi zlatnih svopova potrebno je potpisati ugovor ICMA ${ }^{4}$ ugovor.

Ukoliko pretpostavimo da u ovoj transakciji želimo prodati $64.000 / \mathrm{oz}$ na period od 1 mjeseca, tada možemo da ostvarimo prihod od $0,02 \%$ (forward rate), ali i da dobijena sredstva investiramo u neki drugi vid - depozit ili hartija od vrijednosti, te da na tom osnovu realizujemo prihode. Kako bi se detaljnije pojasnila ova transakcija, potrebno je ukazati na sljedeće podatke:

- Prepostavimo da se zlato investira kroz zlatni svop na rok od 1 mjeseca, na primjer, od 21. februara do 21. marta - što je 28 dana;

- Pretpostavimo da je na posmatrani dan XAU/EUR 5 960,00;

2 Repo poslovi - Suština repo posla jeste u „pozajmljivanju“ hartija od vrijednosti, odnosno, svodi se na kupovinu i prodaju hartija od vrijenosti po unaprijed dogovorenoj cijeni na unaprijed dogovoreni budući datum.

3 LBMA - The London Bullion Market Association)- Londonsko tržište metala

4 ICMA - The International Capital Market Association - organizacija sa "uticajnim glasom" na tžištu kapitala. Pored uticaja na globalnom finansijskom tržištu ova organizacija izdaje globalne ugovore koje učesnice moraju potpisati ukoliko žele obavljati ove poslove.

5 Predstavlja kurs između valute EUR i zlata koji se fiksira, odnosno koji kotira na LMBA.
- To znači da se 21 . februara prodaje $64.000 /$ oz i kupuje EUR 61.440.000 (64.000 x 960,00). Ipak, u ovaj izračun potrebno je uključiti forvard stopu, pretpostavimo da je to $0,02 \%$, te je tako suma nešto drugačija i iznosi EUR $61.440 .960\left(64.000 \times 960,015^{6}\right)$;

- Na dan 21. marta, kada dospije ugovor, centralna banka kupuje 64.000/oz i prodaje EUR 61.440.960.

Kretanje svop stopa na zlato je tokom poslednjih godina značajno smanjeno, što se uočava i iz slike br. 1. Slika pokazuje kretanje cijene zlata i svop stope na jedan mjesec i 12 mjeseci kao i kretanje prinosa na obveznice Njemačke uz dospijeće od 3 i 12 mjeseci. Kako se primjećuje, u momentima prije krize, kada je cijena zlata bila značajno niža nego sada, kamatne stope na zlatne svopove su bile značajno veće i dosezale su do $6 \%$ godišnje. Kako je cijena zlata rasta tako su svop stope bilježile pad i dostigle nivo do $0 \%$, i niže. Suština je u tome da je u situacijama kada je cijena zlata bila relativno stabilna, mnogo atraktivnije bilo investirati u formi svopova na zlato. Kako je došlo do rasta cijene zlata, uporedo sa razvojem finansijske krize, tako su svop stope na zlato smanjene, zajedno sa padom kamatnih stopa na finansijskom tržištu.

Kako se primjećuje, kamatne stope su tokom jačanja krize, a posebno tokom 2014. godine, zabilježile veliki pad, te su zabilježile negativne nivoe. Ipak, kako se iz prikazane slike primjećuje, kamatne stope na svop na zlato su i dalje nešto iznad tih negativnih nivoa, te je to jasan indikator opravdanosti ovih investicija. U sadašnjim uslovima, u kojima je veoma teško investirati i u kojim bilo kakva pozitivna stopa predstvalja opravdano investiranje, jedna od opcija svakako jeste investiranje zlata kroz zlatne svopove. 
osigurani kolateralom te u nekim situacijama postoji mogućnost da se, sa ciljem minimiziranja rizika, koriste kolaterali u formi obveznica. Prema sadašnjim uslovima na tržištu, poslovi investiranja "zlatnih“ depozita se mogu obavljati sa komercijalnim bankama. Sa ciljem detaljnijeg prikaza poslova investiranja „zlatnih“ depozita, korisno je pojasniti na koji način funkcioniše ovaj posao. U suštini, posao investiranja zlatnog depozita je dosta jednostavan i ne razlikuje se značajno od investiranja klasičnih depozita. Transakcija se inicira jednostavnim pozivom komercijalne banke kod koje se želi investirati zlatni depozit, pri čemu banka nudi određenu kamatnu stopu. Kamatna stopa se, kako je i uobičajano, izražava u procentima, ali se obračunava i naplaćuje u uncama. Na primjer, ukoliko bismo 64.000 unci investirali na period od 3 mjeseca, uz kamatnu stopu od 0,25\%, tada bi suma kamate bila sljedeća:

Period investiranja od 19.02. do 19.05. što je 89 dana:

- Kamatna stopa 0,25\%

- Investira se $64.000 / \mathrm{oz}$ $64.000 / \mathrm{oz} \times 0,25 \%$ x $89 / 360=39,555 / \mathrm{oz}$

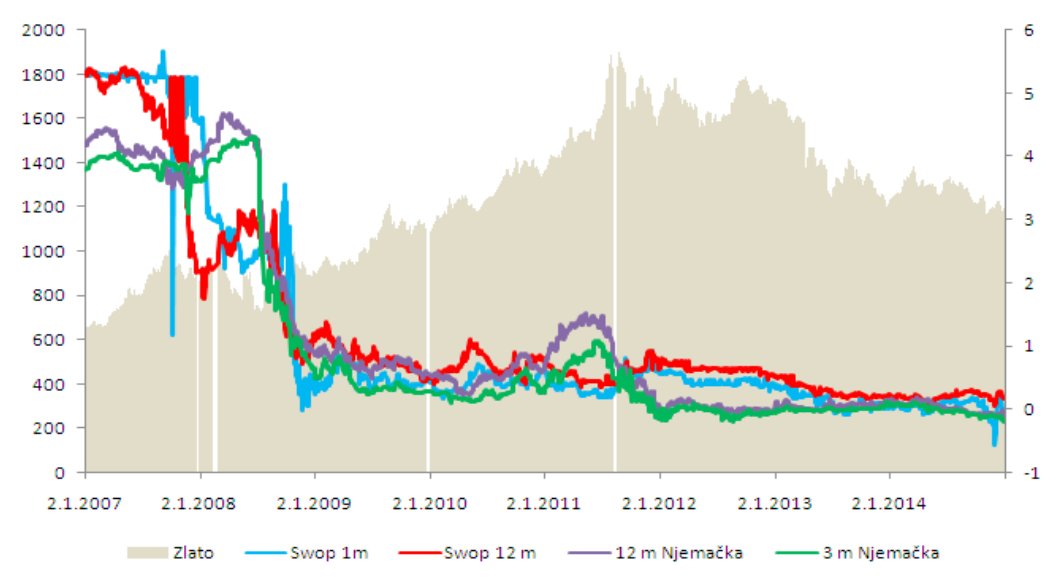

Slika 2. Kretanje cijene zlata, stope na „zlatne“ depozite i prinosi na artije od vrijednosti Njemačke Izvor: Bloomberg

ili pak investicije u državne hartije od vrijednosti. Činjenica je da centralne banke trebaju koristiti mogućnosti, odnosno opcije efikasnijeg investiranja monetarnog zlata, posebno u sadašnjim rekordno niskim prinosima.

\section{LITERATURA}

Dakle, za period investiranja od 86 dana postoji mogućnost da se ostvari zarada, kamata, u sumi od 39,555/oz. Prilikom isplate kamate postoje dvije opcije:

- Ili da se kamata isplati u unacama, koje su zarađene u ovom osnovu,

- Ili da se isplate novčana sredstava u valuti koja odgovara klijentu (valuti koja odgovara centralnoj banci).

Ukoliko želimo da se sredstva isplate u EUR, tada komercijalna banka koristi LMBA fiksing za isplatu ovih sredstava.

Slika 2 pokazuje kretanje kamatne stope na zlatne depozite, kretanje cijene zlata i prinose na hartije od vrijednosti Njemačke. Uočava se postoji isti trend kao i na slici broj 1 na kojoj je analizirano kretanje stopa svopova na zlato. Ipak, stope na svopove i stope na „zlatne“ depozite su nešto visočije u odnosu na prinose hartija od vrijednosti koji su indikator kamatnih stopa na tržištu EU.

\section{ZAKLJUČAK}

Jačanje i razvoj globalne finansijske krize u velikoj je mjeri promjenio investicijske mogućnosti. Centralne banke, kao veoma važni učesnici na finansijskim tržištima, posjeduju zlatne rezerve koje je korisno investirati na različitim osnovama i na taj način ostvariti određene sume prihoda, odnosno zarade. Iako je tokom krize došlo do pada kamatnih stopa na sve aktive, pa tako i na investicije monetarnog zlata, primjećuje se da su ove stope nešto visočije u odnosu na kamatne stope na klasične depozite

Doran, A. (1998). Trends in gold banking. Geneva: World Gold Council.

Harmston, S. (1998). Gold as a store of value. Geneva: World Gold Council.

IMF. (2013). International reserves and foreign currency liquidity: guidelines for a data template. Washington, DC: International Monetary Fund. Preuzeto 12. Februara 2015. sa http://www.imf.org/external/np/sta/ir/IRProcessWeb/pdf/ guide2013.pdf

Michaud, R., Michaud, R.,\& Pulvermacher, K. (2006). Gold as a Strategic Asset. Preuzeto 12. Februara 2015. sa https://www. newfrontieradvisors.com/Research/Articles/documents/ Gold\%20as\%20a\%20Strategic\%20Asset.pdf

Robert, F., Brommecker, R., Bourne, B. T., Dobak, P.J., McEwan, C. J., Rowe, R.R., \& Zhou, X. (2007). Models and Exploration Methods for Major Gold Deposit Types. Proceedings of Exploration 07: Fifth Decennial International Conference on Mineral Exploration, pp. 691-711.

Takeda, H. (2006). Treatment of allocated/unallocated gold held as reserve assets and gold swaps and gold deposits. Preuzeto 12. Februara 2015. sa http://www.imf.org/external/np/sta/ bop/pdf/fu111.pdf

Wright, C., \& Brown, S. (2006). Non-monetry gold. Financial Assets Classification, Issue 44. Preuzeto 12. Februara 2015. sa http://unstats.un.org/unsd/nationalaccount/aeg/papers/ m4Gold.PDF 